\title{
Effect of mutation supply on population dynamics and trait evolution in experimental microbial community
}

\author{
Johannes Cairns ${ }^{1}$, Alexandre Jousset ${ }^{2}$, Lutz Becks ${ }^{3}$, and Teppo Hiltunen ${ }^{4}$ \\ ${ }^{1}$ University of Helsinki \\ ${ }^{2}$ Utrecht University \\ ${ }^{3}$ Universität Konstanz \\ ${ }^{4}$ University of Turku
}

March 4, 2021

\begin{abstract}
Mutation supply can influence eco-evolutionary dynamics in important ways which have received little attention. Mutation supply determines key features of population genetics, such as the pool of adaptive mutations, evolutionary pathways available, and importance of processes such as clonal interference. The resultant trait evolutionary dynamics, in turn, can alter population size and species interactions. However, controlled experiments testing for the importance of mutation supply on rapid adaptation and thereby population and community dynamics are lacking. To close this knowledge gap, we performed a serial passage experiment with wild-type Pseudomonas fluorescens and an isogenic xerD mutant with reduced mutation rate. Bacteria were grown at two resource levels in combination with the presence of a ciliate predator. We found that a higher mutation supply enabled faster adaptation to the low-resource environment and anti-predatory defense. This was associated with higher population size at the ecological level and better access to high-recurrence mutational targets at the genomic level for the strain with higher mutation supply. In contrast, mutation rate did not affect growth under high-resource level, possibly because of more permissive conditions or high population size saturated in mutations. Our results demonstrate that intrinsic mutation rate influences population dynamics and trait evolution particularly when population size is constrained by extrinsic conditions.
\end{abstract}

\section{Hosted file}

MS_Ecol_Lett.pdf available at https://authorea.com/users/398912/articles/511510-effect-ofmutation-supply-on-population-dynamics-and-trait-evolution-in-experimental-microbialcommunity

\section{Hosted file}

SI_Ecol_Lett.pdf available at https://authorea.com/users/398912/articles/511510-effect-ofmutation-supply-on-population-dynamics-and-trait-evolution-in-experimental-microbialcommunity 


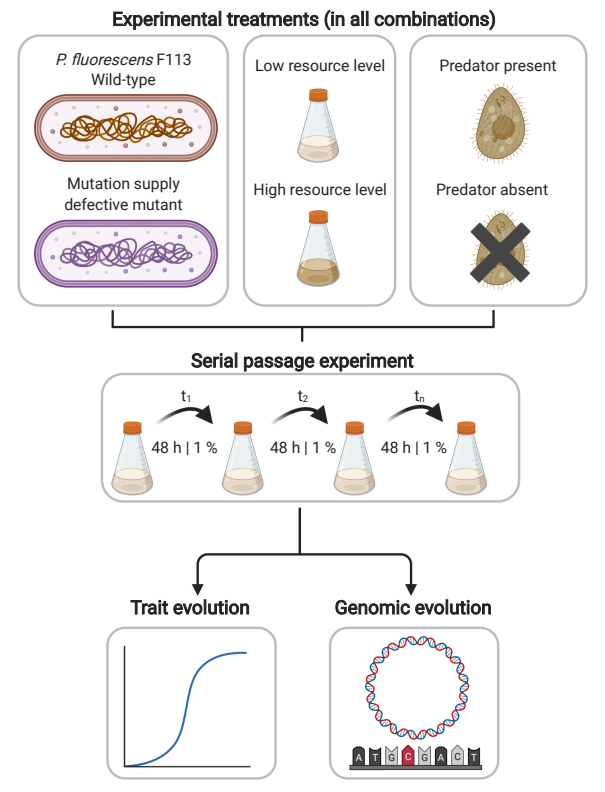

A
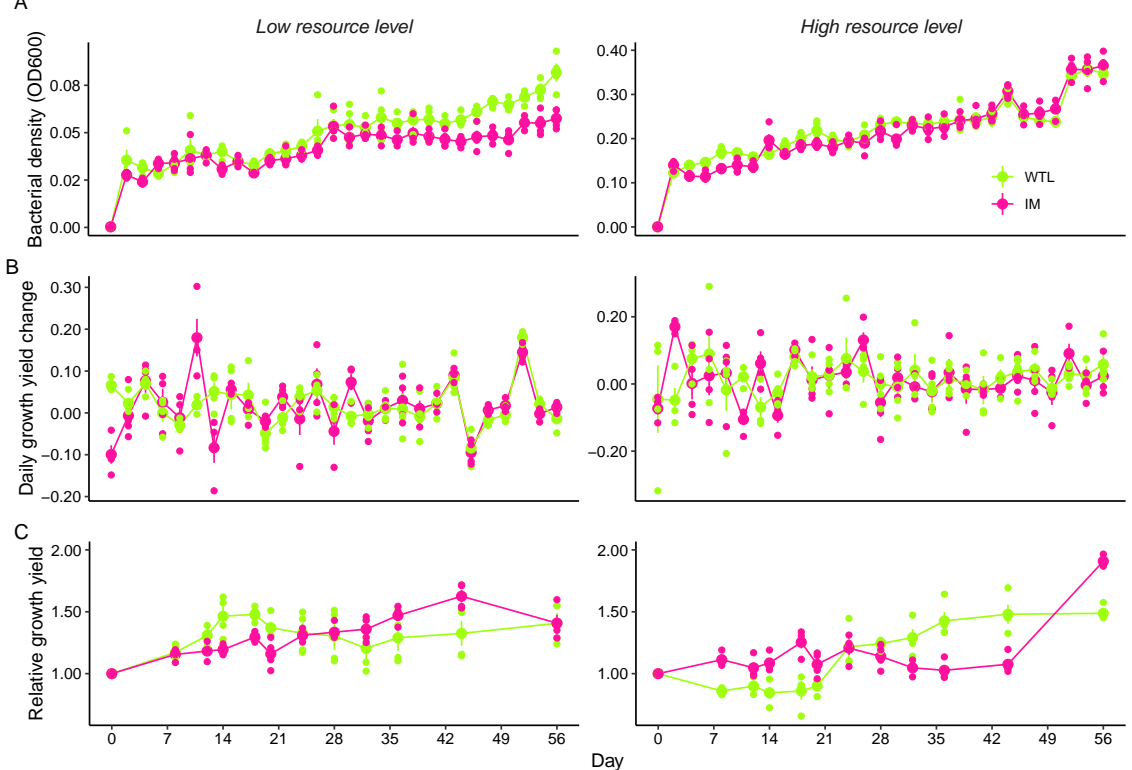
A
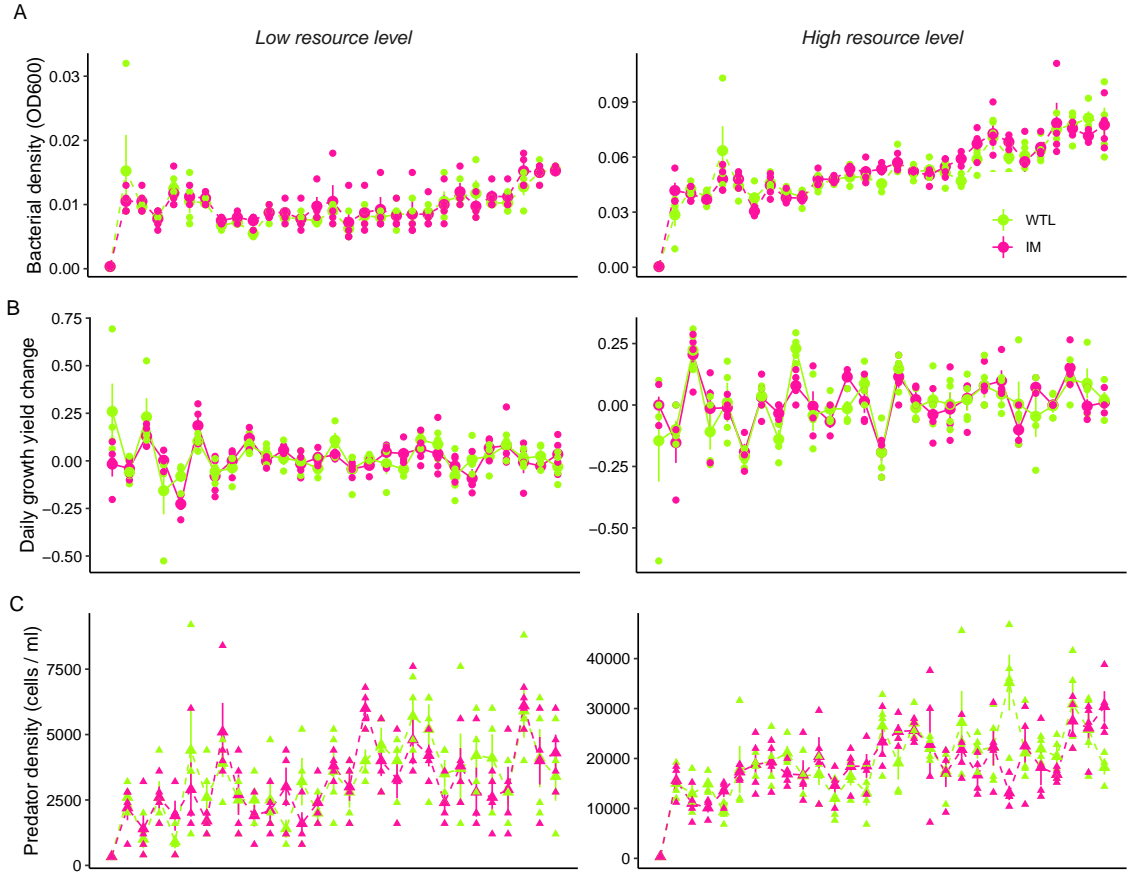

D
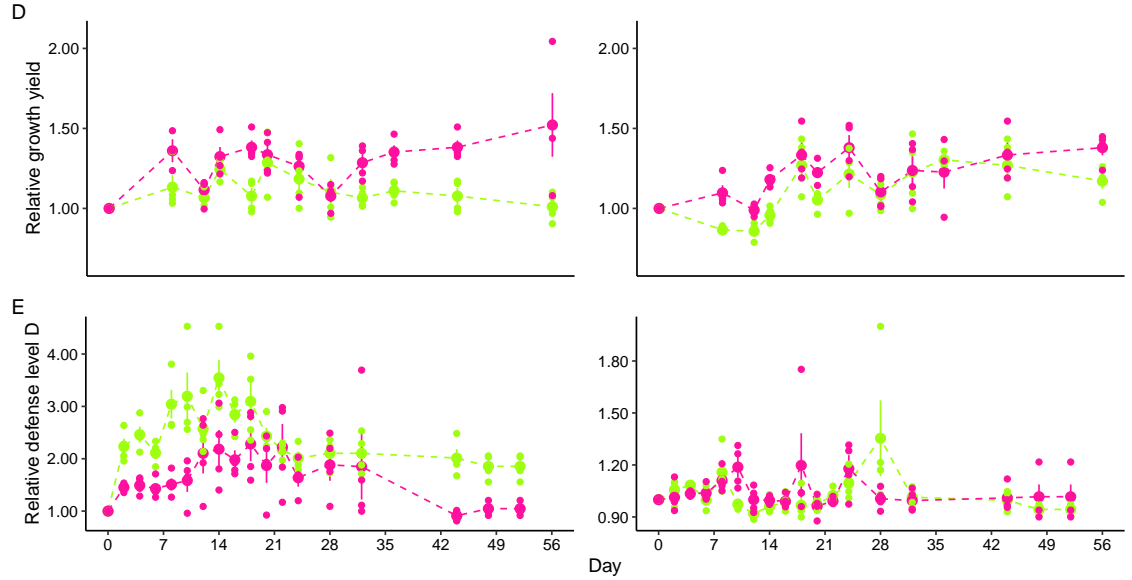


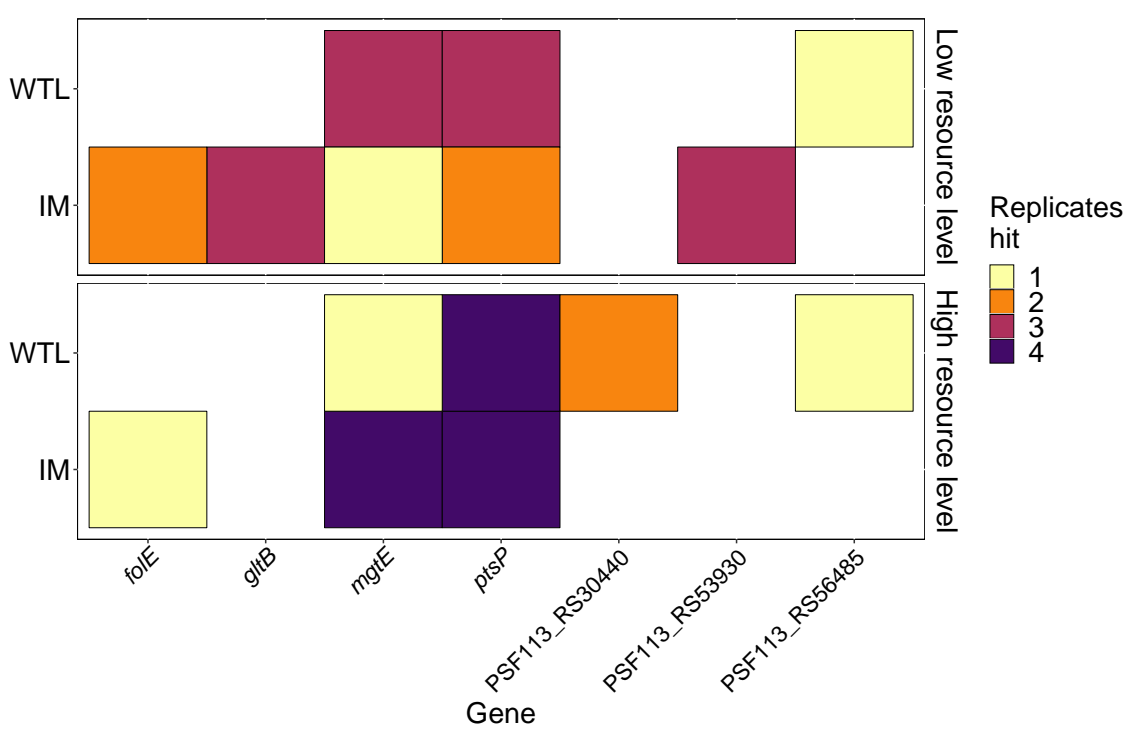

